\title{
Criteria for the prescription of oral bisphosphonates for the treatment of osteoporosis in a series of women referred for tooth extraction
}

\author{
Márcio Diniz-Freitas ${ }^{1}$, Javier Fernández-Feijoo ${ }^{2}$, Paula Fernández-Montenegro ${ }^{2}$, Antonio González-Mosquera ${ }^{2}$, \\ Emma Vázquez-García ${ }^{3}$, Pedro Diz-Dios ${ }^{2}$
}

\begin{abstract}
${ }^{1}$ Oral Medicine and Oral Surgery Unit, Faculty of Medicine and Dentistry, University of Santiago de Compostela, Santiago de Compostela, Spain

${ }^{2}$ Special Needs Unit, Faculty of Medicine and Dentistry, University of Santiago de Compostela, Santiago de Compostela, Spain

${ }^{3}$ Primary Care Buccodental Health Unit, Lérez Health Centre, Pontevedra, Spain. Galician Health Department (SERGAS)
\end{abstract}

Correspondence:

Facultad de Medicina y Odontología

Universidad de Santiago de Compostela

C/Entrerrios s/n

15782 Santiago de Compostela

La Coruña, Spain

marcio.diniz@usc.es

Diniz-Freitas M, Fernández-Feijoo J, Fernández-Montenegro P, GonzálezMosquera A, Vázquez-García E, Diz-Dios P. Criteria for the prescription of oral bisphosphonates for the treatment of osteoporosis in a series of women referred for tooth extraction. Med Oral Patol Oral Cir Bucal. 2012 Jul 1;17 (4):e601-4.

Received: 05/05/2011 Accepted: 16/09/2011

http://www.medicinaoral.com/medoralfree01/v17i4/medoralv17i4p601.pdf

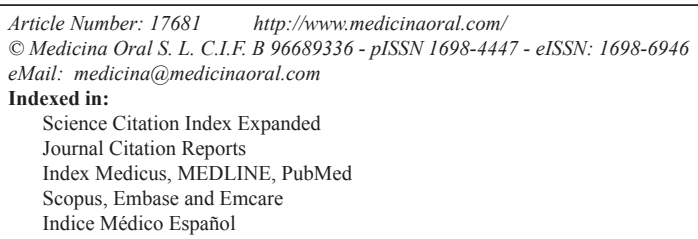

\begin{abstract}
Objective: To evaluate the criteria for the prescription of oral bisphosphonates (OB) in a series of women with osteoporosis referred for tooth extraction.

Study design: The study included 38 postmenopausal women on treatment with OBs. The following variables were analysed: age, weight, height, type of $\mathrm{OB}$ and duration of treatment, bone densitometry and risk factors for osteoporosis. In addition, the osteoporosis self-assessment tool (OST) was administered and collagen type I Ctelopeptide (CTX) levels were measured.

Results: Bone densitometry had only been performed in six patients $(15.7 \%)$ before starting OB treatment. Based on the results of the OST, nine $(23.6 \%)$ of the participants presented a low risk of osteoporosis. CTX levels were measured in 23 patients: 11 (47.8\%) presented values below $150 \mathrm{pg} / \mathrm{ml}$.

Conclusion: Although all patients in the present series were on treatment with OBs, a large percentage did not satisfy the criteria for the initiation of treatment for postmenopausal osteoporosis.
\end{abstract}

Key words: Osteoporosis, oral bisphosphonates, osteonecrosis of the jaws. 


\section{Introduction}

Osteoporosis is defined as a skeletal disorder characterised by a reduction of the bone mass and a structural deterioration of bone tissue, leading to increased bone fragility. It mainly affects postmenopausal women and is associated with significant morbidity due to an increased risk of fractures (1). A number of pharmacological and non-pharmacological therapeutic initiatives have been proposed to prevent and treat postmenopausal osteoporosis. In Spain this has led to a steady increase in recent years in the prescription of drugs to combat the disease, particularly oral bisphosphonates (OB) (2). The efficacy of the OBs is related to their ability to inhibit bone resorption, the clinical correlate of which is a significant reduction in the prevalence of vertebral and non-vertebral fractures in postmenopausal women with osteoporosis (3).

New adverse effects of the prolonged administration of bisphosphonates have been detected in recent years; one of these, particularly important due to its associated morbidity, is osteonecrosis of the jaws (ONJ). Bisphosphonate-related ONJ is defined as an area of bone exposure in the maxillofacial region that persists for more than eight weeks in patients treated with bisphosphonates (at the time of the lesion or previously) and who have not received radiotherapy to that anatomical region. The management of established lesions of ONJ is complex and may require disfiguring surgical treatments with major functional and cosmetic sequelae. Although the relationship between treatment with bisphosphonates and ONJ is based on solid epidemiological evidence, osteonecrosis attributable to the use of OBs has been questioned more than that associated with the intravenous administration of these drugs (4). However, in a recently published retrospective multicentre study it was suggested that the relative frequency of ONJ in patients with osteoporosis treated with OBs is higher than previously estimated (5). Thus, if the prescription of OBs to some patients were not correctly indicated, they would be unnecessarily exposed to an increased risk of ONJ.

As tooth extractions are considered to be the principal trigger of OB-related ONJ (6), the present study was designed to evaluate the criteria applied for the prescription of OB in a series of postmenopausal women attending a dental clinic for tooth extractions.

\section{Material and Methods}

The study group comprised 38 postmenopausal women who were on treatment with OBs for osteoporosis and who came to a primary care buccodental health unit of the Galician Health Service (SERGAS) for tooth extractions during the period between June 2009 and June 2010. The mean age of the participants was $68.7 \pm 7.6$ years (range: $54-92$ years). None of the women devel- oped ONJ after performing the extraction (follow-up period: 3-12 months).

All the patients filled in a standardised health questionnaire to obtain the variables of interest, and the information was completed from a review of their medical histories in the computerised SERGAS data base. The following variables were analysed: age, weight, height, type of $\mathrm{OB}$ and duration of the treatment, bone densitometry study (dual x-ray absorptiometry [DXA]) and risk factors for osteoporosis (Table 1). In addition, the osteoporosis

Table 1. Risk factors for osteoporosis.

\begin{tabular}{|l|c|c|}
\hline $\begin{array}{l}\text { Age (years) } \\
68.7 \pm 7.6 \text { (range: } 54-92)\end{array}$ & $\begin{array}{c}\leq 65 \text { years } \\
14(36.8 \%)\end{array}$ & $\begin{array}{c}>65 \text { years } \\
24(63.1 \%)\end{array}$ \\
\hline History of fractures & $\begin{array}{c}\text { No } \\
26(68.4 \%)\end{array}$ & $\begin{array}{c}\text { Yes } \\
121.5 \%)\end{array}$ \\
\hline $\begin{array}{l}\text { Osteoporosis self-assessment } \\
\text { tool score }\end{array}$ & $\begin{array}{c}\geq 2 \\
\text { Tibia or fibula }=5 / 12 \\
\text { Wrist }=3 / 12 \\
\text { Patella }=2 / 12 \\
\text { Phalanx of a toe }=2 / 12\end{array}$ \\
\hline
\end{tabular}

self-assessment tool (OST) was administered; this estimates the risk of osteoporosis according to the weight and age of the patient. The cut-off point for the referral of patients to perform DXA is a score of 2. Prior to performing the extractions, the serum levels of collagen type I C-telopeptide (CTX) were determined (E 170 Elecsys, Roche Diagnostics, Mannheim, Germany).

This project was approved by the Ethics Committee of the Galician Government and all participants signed a specific informed consent form before their inclusion in the study.

\section{Results}

The most widely used OB in the study group was alendronate $(50 \%)$, followed by risedronate $(23.7 \%)$, ibandronate $(23.7 \%)$ and the combination of alendronate with cholecalciferol (2.6\%). The mean duration of treatment was $42.4 \pm 40.4$ months (range: $2-180$ months); 16 patients $(42.1 \%)$ had been on treatment for more than three years. The risk factors for osteoporosis and bisphosphonate-related ONJ are listed in table 1. Bone densitometry had only been performed in 6 patients (15.7\%) before starting treatment and all of them had a T-Score (comparison of bone mineral density of the patient with that of a healthy individual of 30 years of the same sex and ethnic origin) less than -2.5 (2.5 standard deviations below the referent mean). A history of presumably osteoporotic fractures was detected in 12 patients (31.5\%) (Table 1). Twenty-nine participants $(76.3 \%)$ were at risk of osteoporosis according to the results of the OST (OST 
score $<2$ ). CTX levels were measured in 23 patients and the mean value was $197.7 \mathrm{pg} / \mathrm{ml}$; eight patients (34.8\%) presented values below $100 \mathrm{pg} / \mathrm{ml}$, three $(13 \%)$ presented levels of $100-150 \mathrm{pg} / \mathrm{ml}$ and in the remaining 12 $(52.2 \%)$ the values were over $150 \mathrm{pg} / \mathrm{ml}$ (Table 2).

Table 2. Risk factors for bisphosphonate-related osteonecrosis of the jaws in the present series.

\begin{tabular}{|l|c|c|c|}
\hline $\begin{array}{l}\text { Duration of treatment with } \\
\text { oral bisphosphonates }\end{array}$ & $\begin{array}{c}<3 \text { years } \\
22(57.9 \%)\end{array}$ & $\begin{array}{c}\geq 3 \text { years } \\
16(42.1 \%)\end{array}$ & \\
\hline $\begin{array}{l}\text { Serum LEVELS OF collagen } \\
\text { type I C-telopeptide* }\end{array}$ & $\begin{array}{c}\text { High risk } \\
<100 \mathrm{pg} / \mathrm{ml} \\
8(34.8 \%)\end{array}$ & $\begin{array}{c}\text { Moderate risk } \\
100 \mathrm{pg} / \mathrm{ml} \\
3(13 \%)\end{array}$ & $\begin{array}{c}\text { Low risk } \\
>150 \mathrm{pg} / \mathrm{ml} \\
12(52.2 \%)\end{array}$ \\
\hline $\begin{array}{l}\text { Long-term corticosteroid } \\
\text { treatment }\end{array}$ & $\begin{array}{c}\text { Yes } \\
3(7.9 \%)\end{array}$ & $\begin{array}{c}\mathrm{No} \\
35(92.1 \%)\end{array}$ & \\
\hline
\end{tabular}

*CTX levels were measured in 23 patients.

\section{Discussion}

In recent years there has been an alarming increase in the number of cases of ONJ in patients treated with OBs. Many of these patients present a poor oral health status (in the present series, $35.5 \%$ of the patients had calculus and the depth of periodontal probing was greater than 6 $\mathrm{mm}$ in $16.1 \%$ ), meaning they have considerable requirements for dental treatment, including tooth extractions. This dental procedure is considered to be the most common triggering factor for OB-related ONJ (6). The management of established ONJ lesions is complex and the clinical course is difficult to predict; prevention and the control of risk factors is thus very important. One of the initial strategies to prevent ONJ associated with the administration of OBs to patients with osteoporosis would therefore be appropriate supervision of the prescription of these drugs.

Bone mineral density (BMD) is fundamental to the decision on whether or not to start pharmacological treatment of osteoporosis (7). DXA of the lumbar column and/or of the hip is the most reliable technique to determine the BMD (8) and the World Health Organisation defines osteoporosis as a BMD T-score equal to or less than -2.5. Numerous guidelines, protocols and recommendations on strategies for the prevention and treatment of osteoporosis have been published, but the indication for densitometry continues to be a subject of controversy. In general, pharmacological treatment is administered to patients with a BMD T-Score equal to or less than -2.5 , to those with a BMD T-score less than -2 in association with multiple risk factors, and to those with a history of osteoporotic fractures of the vertebral column or of the hip (9). Although a decrease in the BMD represents one of the most important risk factors for fractures due to osteoporosis, DXA had only been performed in $15 \%$ of patients in the present study. Another risk indicator commonly used to justify the ini- tiation of pharmacological treatment for osteoporosis is a history of vertebral or hip fractures; this risk factor was not detected in any of the patients evaluated in the present study, although $31.5 \%$ of them presented fractures presumably of osteoporotic origin at other sites. In a recently published study performed by Felipe et al. (10) in a primary care centre in Parla, Madrid, Spain, it was found that only $51.8 \%$ of patients who were receiving treatment for osteoporosis satisfied the prescription criteria. On reviewing the medical histories, those authors found no record of a DXA scan in the majority of cases $(73.1 \%)$ and that $39.5 \%$ of the patients had suffered at least one osteoporotic fracture. It was suggested that these results could be indicative of the difficulty of access to DXA in the Spanish national health system. As it is not feasible to determine the BMD in all at-risk patients in many countries in which access to DXA is not straightforward, a number of clinical-decision tools, principally in the form of simple questionnaires on the risk factors for osteoporosis, have been designed to identify those women with a low BMD who should be referred for DXA. In the present study we used the OST, as this is considered to be a useful index for identifying postmenopausal women with a low BMD (11). Based on the OST scores, $23.6 \%$ of the patients evaluated were classified as being at low risk and therefore referral for DXA would not be indicated.

The measurement of CTX levels has been recommended to establish the risk of bisphosphonate-related ONJ and to aid decision-taking in the dental setting, particularly with respect to surgical procedures (12). However, the usefulness of this parameter has subsequently been questioned and some authors do not consider it should be used routinely for this purpose $(13,14)$. In a recently published study by Lazarovici et al. (15), it was demonstrated that there was a five-fold increase in the risk of developing bisphosphonate-related ONJ in subjects with CTX levels below $150 \mathrm{pg} / \mathrm{ml}$ compared to individuals with higher levels. Although $47.8 \%$ of the patients in the present study were identified as being at high risk according to the criteria proposed by Marx et al. (12), none developed ONJ after tooth extraction.

Osteoporosis is a major public health problem because it significantly increases the risk of fractures, particularly in untreated patients. In general, it is accepted that the benefits derived from treatment with OBs are greater than the relatively small risk of developing ONJ. Although all the patients in the present series were receiving OBs, the majority did not satisfy the criteria for the initiation of treatment for postmenopausal osteoporosis. Different protocols for the treatment of osteoporosis in postmenopausal women have been proposed aid decision-taking in the two most controversial aspects of osteoporosis: in which patients to perform DXA and in which to start pharmacological treatment $(1,9)$. Adher- 
ence to standardised guidelines for the prescription of OBs in postmenopausal women could therefore help to improve the management of osteoporosis and reduce the prevalence of ONJ secondary to dental procedures.

\section{References}

1. Grupo de trabajo de la Sociedad Española de Investigaciones Óseas y Metabolismo mineral. Postmenopausal osteoporosis. Clinical practice guide. Rev Clin Esp. 2003;203:496-506.

2. Erviti J. Drugs prescription for osteoporosis. An Sist Sanit Navar. 2003;26:107-21

3. Chapurlat RD, Delmas PD. Drug insight: Bisphosphonates for postmenopausal osteoporosis. Nat Clin Pract Endocrinol Metab. 2006;2:211-9.

4. Ruggiero SL, Dodson TB, Assael LA, Landesberg R, Marx RE, Mehrotra B. American Association of Oral and Maxillofacial Surgeons position paper on bisphosphonate-related osteonecrosis of the Jaws-2009 update. J Oral Maxillofac Surg. 2009;67:2-12.

5. Otto S, Abu-Id MH, Fedele S, Warnke PH, Becker ST, Kolk A, et al. Osteoporosis and bisphosphonates-related osteonecrosis of the jaw: Not just a sporadic coincidence -a multi-centre study. J Craniomaxillofac Surg. 2011;39:272-7.

6. Yarom N, Yahalom R, Shoshani Y, Hamed W, Regev E, Elad S. Osteonecrosis of the jaw induced by orally administered bisphosphonates: incidence, clinical features, predisposing factors and treatment outcome. Osteoporos Int. 2007;18:1363-70.

7. Bergmann P, Body JJ, Boonen S, Boutsen Y, Devogelaer JP, Goemaere $\mathrm{S}$, et al. Evidence-based guidelines for the use of biochemical markers of bone turnover in the selection and monitoring of bisphosphonate treatment in osteoporosis: a consensus document of the Belgian Bone Club. Int J Clin Pract. 2009;63:19-26.

8. Assessment of fracture risk and its application to screening for postmenopausal osteoporosis. Report of a WHO Study Group. World Health Organ Tech Rept Ser. 1994;843:1-129.

9. Gass M, Dawson-Hughes B. Preventing osteoporosis-related fractures: an overview. Am J Med. 2006;119:S3-S11.

10. de Felipe R, Cáceres C, Cimas M, Dávila G, Fernández S, Ruiz T. Clinical characteristics of patients under treatment for osteoporosis in a Primary Care Centre. Who do we treat? Aten Primaria. 2010;42: $559-63$.

11. McLeod KM, Johnson CS. Identifying women with low bone mass: A systematic review of screening tools. Geriatr Nurs. 2010;30:164-73

12. Marx RE, Cillo JE Jr, Ulloa JJ. Oral bisphosphonate-induced osteonecrosis: risk factors, prediction of risk using serum CTX testing, prevention, and treatment. J Oral Maxillofac Surg. 2007;65:2397-410. 13. Baim S, Miller PD. Assessing the clinical utility of serum CTX in postmenopausal osteoporosis and its use in predicting risk of osteonecrosis of the jaw. J Bone Miner Res. 2009;24:561-74.

14. Cardona F, Bagán JV, Sáinz E, Figuerido J, Giner F, Vidán FJ.

[Bisphosphonate-related osteonecrosis of the jaws. An update]. An Sist Sanit Navar. 2009;32:413-21.

15. Lazarovici TS, Mesilaty-Gross S, Vered I, Pariente C, Kanety H, Givol N, et al. Serologic bone markers for predicting development of osteonecrosis of the jaw in patients receiving bisphosphonates. J Oral Maxillofac Surg. 2010;68:2241-7. 